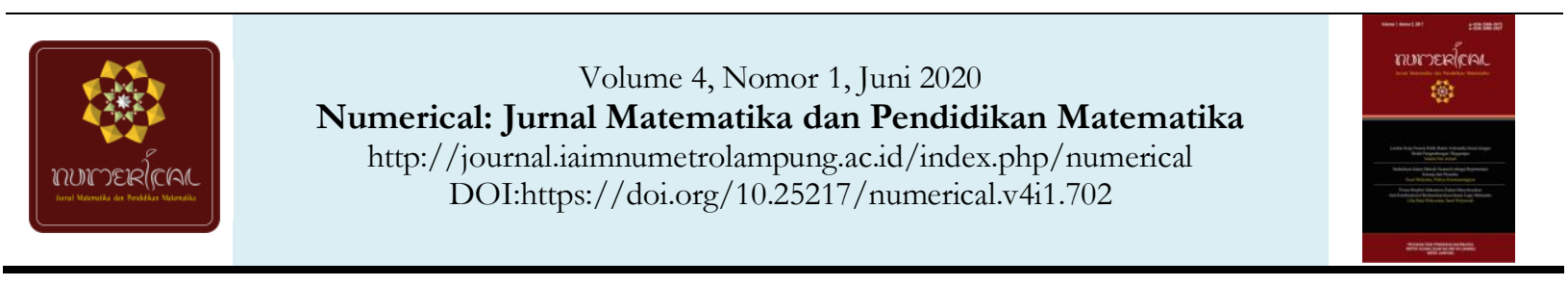

\title{
Eigen Problem Over Max-Plus Algebra on Determination of the T3 Brand Shuttlecock Production Schedule
}

\author{
Andra Permana ${ }^{1}$, Siswanto $^{2}$, Pangadi ${ }^{3}$
}

1, 2,3 Universitas Sebelas Maret Surakarta, Indonesia

Correspondence: $\triangle$ nikiemailkula@gmail.com

Article Info

Article History

Received: 06-01-2020

Revised: 07-06-2020

Accepted: 08-06-2020

Keywords:

Max-Plus Algebra;

Production System;

Scheduling

\section{Abstract}

The production process is included in the Discrete Event System (DES). The DES independent variable generally depends on the event, so an event is influenced by the previous event. Max-plus algebra can be applied in the DES problem to change the system of nonlinear equations obtained into linear equations. Max-plus algebra is a set of real numbers $\mathbb{R}$ combined with $\varepsilon=-\infty$ equipped with operations max $\bigoplus$ and plus $\otimes$ or can be denoted $\left(\mathbb{R}_{\varepsilon}, \oplus, \otimes\right)$ with $\mathbb{R}_{\varepsilon}=\mathbb{R} \cup\{\varepsilon\}$. An effective and efficient production process needs to pay attention scheduling steps well. The purpose of this research is to determine the Shuttlecock T3 production schedule using eigenvalue and eigenvector in max-plus algebra. The research method in this research is study of literature and observation. Literature study is carried out by studying references about max-plus algebra, especially material related to scheduling problems, while observation are carried out in the process of taking data of the Shuttlecock T3 production process in Surakarta. The linear equation system that is formed based on the results of the observation is then presented in the form $x(k+1)=A \otimes x(k) \oplus B \otimes u(k+1)$ and $y(k)=C \otimes x(k)$. The periodic time and initial system production time are determined from the eigenvalue and eigenvector matrix $\bar{A}$ where $\bar{A}=A \oplus B \otimes C$. The results of the research showed that the production system run periodically every 249 minutes, then the best time for each processing unit to start working can be determined, as well as the Shuttlecock T3 production schedule according to the working hours more effective and efficient can be determined too.

\section{PRELIMINARY}

Every company cannot avoid competition with other companies. Other companies in this case are known as competitors, namely companies that offer almost similar goods or services [4]. Competition between companies not only gives a negative influence on the perpetrators, but also gives a positive influence in the form of the development of the industrial world as it is today. A company is trying to improve product quality according to consumer demand and carry out the production process effectively and efficiently in order to win trade competition. An effective and efficient production process needs to pay attention to the steps of planning, monitoring and scheduling properly. The production process forms a complex system, this system is included in the Discrete Event System (DES).

According to Silva [10], DES is a subject of the discipline of systems theory and control that includes man-made systems with a finite amount of resources. Existing resources are used by several users to get the best results. The DES independent variable generally depends on the event, not on time, so that an event is influenced by a previous event, not by the current time. Nowak [7] also explained that DES can be used to solve problems such as determining production schedules. Max-plus algebra can be applied to the problem to change the system of nonlinear equations obtained from the problem model into a system of linear equations so that it 
is easily solved. The concept of Eigen values and Eigen vectors, or what is referred to as Eigen value over max-plus algebra, can also be used as a reference in determining the schedule of a production system.

One product that develops in Surakarta is shuttlecock. The shuttlecock industry is a superior product in the Serengan area, which is one of the districts in Surakarta. Shuttlecock craftsmen in the area reach hundreds of people. The T3 brand sshuttlecock, which was established in 1988, is one of the industries which has enlivened the market in the area. The longer the demand for shuttlecocks in the area around Surakarta increased. This increase in demand needs to be supported by improving production system management. Determination of an effective and efficient production schedule is one of the requirements for good management so that this problem then becomes the basic idea of the research and the main objective of this research.

Research Kamceva [3] explained that max-plus algebra could complete the DES model. Then Mursyidah [6] and Sulistyaningsih [12] has also explained that max-plus algebra can be used to solve scheduling problems. Furthermore, in 2016 Sari and Pradanti [9] examined the application of max-plus algebra in a simple leather bag production system, in the same year Muntohar [5] researched the application of max-plus algebra in scheduling the Solopos general daily production system at PT. Solo Grafika Utama.

Some of these studies still use a small number of processors and the type of production system used is still serial and parallel with one input. In contrast to previous studies, in this study more processors were used, namely 20 units and the research object was converted into a production process on a $\mathrm{T} 3$ brand shuttlecock that uses an assembly type production system with two inputs in it so that it better illustrates the real problem in the field. Based on the background of the problem, the formulation of the problem is determined by constructing a matrix from the flowchart, solving Eigen problems, determining the production schedule, and knowing the effect of applying the production schedule.

\section{METHOD}

The research method used in this research is a field study by conducting the data collection process in the form of the T3 brand shuttlecock production flow in Surakarta and the work time of each processor. The steps that will be carried out in this research, namely starting with the T3 brand shuttlecock production process data flow and the working time of each processor, then making a production process flowchart from the data obtained and building a matrix of max-plus algebra. The matrix formed is then determined by the Eigen value and eigenvector vector as a reference in determining an effective, efficient and periodically repeatable shuttlecock production schedule.

\section{RESULT AND DISCUSSION}

Based on the results of the field study, the flow data of the T3 brand shuttlecock production process and the working time of each processor are shown in Table 1. The T3 brand shuttlecock production process consists of 20 processing units namely $P_{1}, P_{2}, P_{3}, \ldots, P_{20}$. The processing time needed for processors $P_{1}, P_{2}, P_{3}, \ldots, P_{20}$ are $d_{1}, d_{2}, d_{3}, \ldots, d_{20}$ in minutes. There are two inputs in it, namely the input of raw materials in the form of feathers and the second input is 
the basic material for making hubcaps. The processing time of each processor is obtained by taking the average value of four times manually sampled data in the field.

Table 1. Production Flow of T3 Brand Shuttlecocks and Time of Each Process

\begin{tabular}{clc}
\hline $\mathrm{P}_{\mathrm{i}}$ & \multicolumn{1}{c}{ Process } & $\mathrm{d}_{\mathrm{i}}($ minute $)$ \\
\hline $\mathrm{P}_{1}$ & Feather Printing & 26 \\
$\mathrm{P}_{2}$ & Cutting fur & 30 \\
$\mathrm{P}_{3}$ & Fur Wash & 10 \\
$\mathrm{P}_{4}$ & Drying Fur & 14 \\
$\mathrm{P}_{5}$ & Sorting Fur & 6 \\
$\mathrm{P}_{6}$ & Hair Straightening & 32 \\
$\mathrm{P}_{7}$ & Make Hubcaps & 8 \\
$\mathrm{P}_{8}$ & Feathering on Hubcaps & 36 \\
$\mathrm{P}_{9}$ & Gluing Fur with Hubcaps & 6 \\
$\mathrm{P}_{10}$ & Tie the Fur & 34 \\
$\mathrm{P}_{11}$ & AdjustmentShuttlecock & 14 \\
$\mathrm{P}_{12}$ & StampingShuttlecock & 2 \\
$\mathrm{P}_{13}$ & Thread Gluing & 6 \\
$\mathrm{P}_{14}$ & Drying & 10 \\
$\mathrm{P}_{15}$ & Quality Control & 12 \\
$\mathrm{P}_{16}$ & Sorting Based on Quality & 6 \\
$\mathrm{P}_{17}$ & Labeling & 1 \\
$\mathrm{P}_{18}$ & Insert Shuttlecock in Slope & 2 \\
$\mathrm{P}_{19}$ & Packing & 1 \\
$\mathrm{P}_{20}$ & Sealing & 1 \\
\hline
\end{tabular}

Then the production flow chart based on the results of the field study is shown in Figure 1. This flow chart can facilitate the construction of a non linear equation system model that describes the T3 brand shuttlecock production system [13].

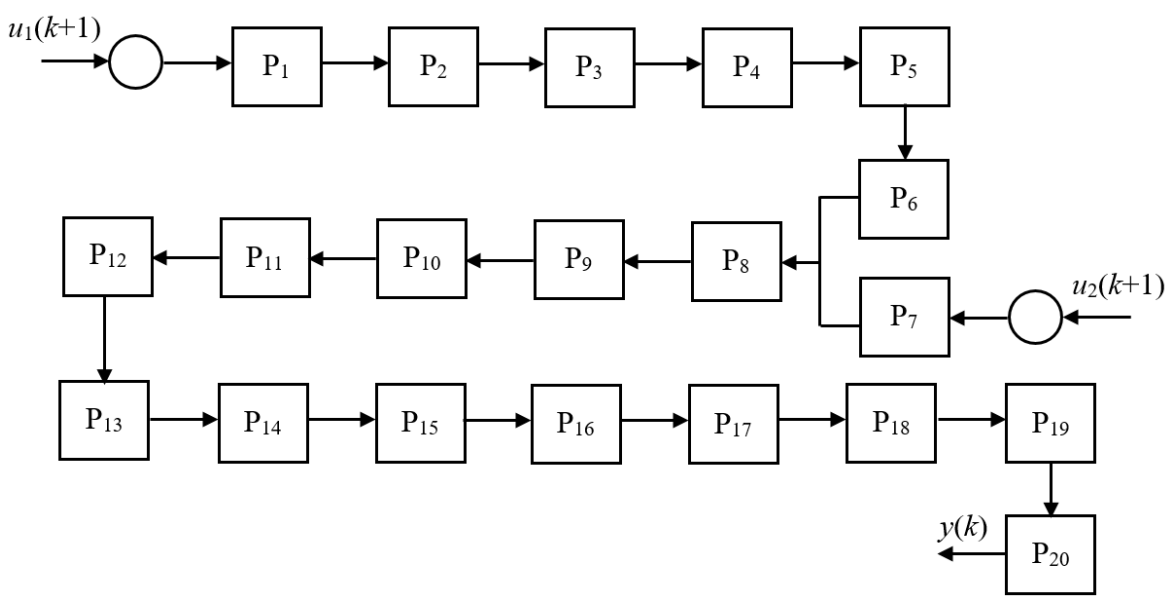

Figure 1. T3 Shuttlecock Production Flowchart 
The form of the development of this research appears in Figure 1 that the data represented in chart form is the type of assembly shown in the $P_{6}$ and $P_{7}$ branches. Previously Muntohar [5] in his research only used serial types so that no branching was found in the process. Furthermore, there are two raw material inputs, namely at $u_{1}(k+1)$ and $u_{1}(k+1)$ which were also not found in previous studies. Defined the T3 brand shuttlecock production system as follows

1. $u(k+1)$ is the time when raw material enters the system for process $(k+1)$ with $k=$ $1,2,3, \ldots$,

2. $x_{i}(k)$ is the time when the unit $i$ starts working for the process $k$ with $i=1,2,3, \ldots, 20$, and

3. $y(k)$ is the time product leaves the system for process $k$.

In some previous studies the maximum amount of data used was only 12 units so that a square matrix with order 12 would be formed, whereas in this research data 20 data processing units would be used so that the matrix number 20 would be formed. Determination of the time $P_{1}$ started working on process to $(k+1)$ is explained as follows. If the raw material is entered into the system for process $(k+1)$, then the raw material is available as input $P_{1}$ at time $u_{1}(k+$ 1. However, $P 1$ can only start working to process the raw material if $P 1$ has completed the previous process, the $k$-th process. Because the processing time needed for $P_{1}$ is $d_{1}=26$ minutes, the semi-finished product from $P_{1}$ leaves $P_{1}$ when $x_{1}(k)+26$. The time obtained when $P_{1}$ starts working for process to $(k+1)$ is

$$
x_{1}(k+1)=\max \left\{x_{1}(k)+26, u_{1}(k+1)\right\}=26 \otimes x_{1}(k) \oplus u_{1}(k+1) .
$$

And so on in the same way for $P_{2}, P_{3}, P_{4}, \ldots, P_{20}$ so that 20 linear equations are obtained for maxplus algebra. The system of equations obtained is then modified in matrix operations on algebra max plus as described Gyamerah [2], it becomes a form

$$
\begin{gathered}
\boldsymbol{x}(k+1)=A \otimes \boldsymbol{x}(k) \oplus B \otimes \boldsymbol{u}(k+1) \\
y(k)=C \otimes \boldsymbol{x}(k) .
\end{gathered}
$$

It is assumed that the time when raw materials enter the system together with the time when the product leaves the system, or can be written $u(k+1)=y(k)$ so that obtained $\bar{A}=$ $[A \oplus B \otimes C]$.. Then the production process schedule can be formed by determining the periodic time of the production process from the Eigen values of matrix $\bar{A}$ and the starting time of each processor starts working is determined from the eigenvector matrix $\bar{A}$ [8]. Using the algorithm described by Subiono [11] and Awallia [1] and using the help of Scilab software, the results as shown in Figure 2. These results require more iterations compared to previous studies, because the amount of data is greater and the type of matrix may be reducible so that the existence and singularity of Eigen values need to be checked first.



Figure 2. EigenvalueandEigenvector of Matrix $\bar{A}$ 
The initial time the system starts working is selected with an eigenvector that has a minimum non-negative component so that the finished process and available materials can be processed immediately. An eigenvector with a minimum non-negative component is obtained when the smallest Eigen vector component is converted to zero [7]. The eigenvector $v^{\prime}$ which has the minimum non negative component is obtained by taking $\alpha=-26$ so that $v^{\prime}$ is obtained as in Figure 3 .

$$
v^{\prime}=\left(\begin{array}{llllllllllllllllllll}
0 & 26 & 56 & 66 & 80 & 86 & 86 & 118 & 154 & 160 & 194 & 208 & 210 & 216 & 226 & 238 & 244 & 245 & 247 & 248
\end{array}\right)^{T}
$$

Figure 3. Corresponding Eigen Vector

So for each processing unit will work periodically with a period $\lambda(\bar{A})=249$ minutes and the processing units $P_{2}, P_{3}, P_{4}, \ldots, P_{20}$ successively work for the first process at minute $0,26,56, \ldots, 248$. The full production schedule is shown in Table 2 .

Table 2. Production Schedule in Minutes

\begin{tabular}{ccc}
\hline \multirow{2}{*}{ Process } & \multicolumn{2}{c}{ Phase } \\
\cline { 2 - 3 } & 1 & 2 \\
\hline $\mathrm{P}_{1}$ & 0 & 249 \\
$\mathrm{P}_{2}$ & 26 & 275 \\
$\mathrm{P}_{3}$ & 56 & 305 \\
$\mathrm{P}_{4}$ & 66 & 315 \\
$\mathrm{P}_{5}$ & 80 & 329 \\
$\mathrm{P}_{6}$ & 86 & 335 \\
$\mathrm{P}_{7}$ & 86 & 335 \\
$\mathrm{P}_{8}$ & 118 & 367 \\
$\mathrm{P}_{9}$ & 154 & 403 \\
$\mathrm{P}_{10}$ & 160 & 409 \\
$\mathrm{P}_{11}$ & 194 & 443 \\
$\mathrm{P}_{12}$ & 208 & 457 \\
$\mathrm{P}_{13}$ & 210 & 459 \\
$\mathrm{P}_{14}$ & 216 & 465 \\
$\mathrm{P}_{15}$ & 226 & 475 \\
$\mathrm{P}_{16}$ & 238 & 487 \\
$\mathrm{P}_{17}$ & 244 & 493 \\
$\mathrm{P}_{18}$ & 245 & 494 \\
$\mathrm{P}_{19}$ & 247 & 496 \\
$\mathrm{P}_{20}$ & 247 & 497 \\
\hline & &
\end{tabular}

From Table 2, it can be converted into working hours to be more representative in accordance with the actual situation on the ground. Based on the results of the field study, the T3 brand shuttlecock starts at $07.30 \mathrm{WIB}$ so that the 0 -th minute in Table 2 can be represented that 
the first processor $\left(P_{1}\right)$ starts working at $07.30 \mathrm{WIB}$ and so on for the other processors. The production schedule after referring to working hours is shown in Table 3.

Table 3. Production Schedule of T3 Brand Shuttlecock

\begin{tabular}{ccc}
\hline \multirow{2}{*}{ Process } & \multicolumn{2}{c}{ Time to Start Production (WIB) } \\
\cline { 2 - 3 } & Phase1 & Phase 2 \\
\hline $\mathrm{P}_{1}$ & 07.30 & 11.39 \\
$\mathrm{P}_{2}$ & 07.56 & 12.05 \\
$\mathrm{P}_{3}$ & 08.26 & 12.35 \\
$\mathrm{P}_{4}$ & 08.36 & 12.45 \\
$\mathrm{P}_{5}$ & 08.50 & 12.59 \\
$\mathrm{P}_{6}$ & 08.56 & 13.05 \\
$\mathrm{P}_{7}$ & 08.56 & 13.05 \\
$\mathrm{P}_{8}$ & 09.28 & 13.37 \\
$\mathrm{P}_{9}$ & 10.04 & 14.13 \\
$\mathrm{P}_{10}$ & 10.10 & 14.19 \\
$\mathrm{P}_{11}$ & 10.44 & 14.53 \\
$\mathrm{P}_{12}$ & 10.58 & 15.07 \\
$\mathrm{P}_{13}$ & 11.00 & 15.09 \\
$\mathrm{P}_{14}$ & 11.06 & 15.15 \\
$\mathrm{P}_{15}$ & 11.16 & 15.25 \\
$\mathrm{P}_{16}$ & 11.28 & 15.37 \\
$\mathrm{P}_{17}$ & 11.34 & 15.43 \\
$\mathrm{P}_{18}$ & 11.35 & 15.44 \\
$\mathrm{P}_{19}$ & 11.37 & 15.46 \\
$\mathrm{P}_{20}$ & 11.38 & 15.47 \\
\hline
\end{tabular}

Based on Table 3, it is known that in one working day two production processes can be carried out. The first starts at $07.30 \mathrm{WIB}$ and then the second production starts at $11.39 \mathrm{WIB}$. Using the production schedule in Table 3 allows the T3 brand shuttlecock business owner to know when a good start time to start each processor works and the production process can run periodically.

\section{CONCLUSIONS AND RECOMMENDATION}

This research produces the T3 brand shuttlecock production schedule. The production schedule makes the production process more effective and efficient because in the production process, the idle processor will immediately start the next process. In terms of management it also makes it easy for T3 brand shuttlecock business owners to know when a good start time to start each processor works and the production process can run periodically. However, this research is still limited to the assumption that the time when raw materials enter the system together with the time when products leave the system. Therefore, further research is needed so that it can refine these assumptions to better suit real-world events. 


\section{REFERENCES}

[1] Awallia, A. R., Siswanto, Kurniawan, V. Y., "Interval Min-Plus Algebraic Structure and Matrices Over Interval Min-Plus Algebra," Journal of Physics: Conference Series, vol. 1494, 2020.

[2] Gyamerah, S. A., Boateng, P. K., and Harvim, P., "Max-plus Algebra and Application to Matrix Operations," British Journal of Mathematics \& Computer Science, vol. 12, pp. 1-14, 2016.

[3] Kamceva, E. , Z. Gacovski, and O. Iliev, Modelling of Queues by Usingof Petri Net Simulator, Institute of Informatics, Faculty of Natural Sciencesand Mathematics, Ss. Cyril and Methodius University in Skopje, Macedonia, 2011.

[4] Kasmir, Kewirausahaan, Jakarta: PT Raja Grafindo Persada, 2012.

[5] Muntohar, A., Penerapan Aljabar Maks-Plus pada Penjadwalan Sistem Produksi Harian Umum Solopos di PT. Solo Grafika Utama, Tugas Akhir S1 Matematika Fakultas MIPA UNS, 2015.

[6] Mursyidah, H. and Subiono, "Eigenvalue, Eigenvector, Eigenmode of Reducible Matrix and Its Application", AIP Conference Proceedings, AIP Publishing, Vol. 1867, Ser.020044, 2017.

[7] Nowak, A. W., The Tropical Eigenvalue-Vector Problem from Algebraic, Graphical, and Computational Perspectives, A Thesis Submitted to the University of Bates Colleges for the Degree of Doctor of Philosophy (PHD), 2014.

[8] Sadiq, A., F. Ahmad, S.A. Khan, J.C. Valverde, T. Naz, and M.W. Anwar, "Modeling and Analysis of Departure Routine In Air Traffic Control Based on Petri Nets," Neural Computing and Applications, vol. 25, pp. 1099-1109, 2014.

[9] Sari, M. R. A. and Pradanti, P., "Penerapan Aljabar Max-Plus pada Sistem Produksi Sederhana Tas Kulit," Seminar Nasional Aljabar Universitas Sanata Dharma dan Kelompok Peminat Aljabar, Yogyakarta, 2016.

[10] Silva, M., "On the history of Discrete Event Systems," Annual Reviews in Control, vol. 45, pp. 213-222, 2018.

[11] Subiono, Aljabar Min-Max-Plus dan Terapannya, Surabaya: Institut Teknologi Sepuluh November, 2015.

[12] Sulistyaningsih, T., Siswanto, Pangadi, "Petri Net Model and Max-Plus Algebra on Queue in Clinic UNS Medical Center", Journal of Physics: Conference Series, vol. 1494, 2020.

[13] Tam, K.P., "Optimizing and Approximating Eigenvectors in Max Algebra," thesis Submitted to the University of Birmingham for The Degree of Doctor of Philosophy (PHD), 2010. 
Numerical: Jurnal Matematika dan Pendidikan Matematika, 4(1), Juni 2020, 23-30 Andra Permana, Siswanto, Pangadi 
Numerical: Jurnal Matematika dan Pendidikan Matematika, 4(1), Juni 2020, 23-30 Andra Permana, Siswanto, Pangadi 